\title{
WILEY
}

\section{EUROPEAN POLICY ANALYSIS}

\section{A Long-Term Perspective on Entrepreneurial Strategies and their Impact on British Road Policy}

\begin{tabular}{|r|l|}
\hline Journal: & European Policy Analysis \\
\hline Manuscript ID & EPA-03-19-0004.R2 \\
\hline Weywords: $:$ & $\begin{array}{l}\text { Policy Entrepreneur, Entrepreneurial Strategies, Expertise, Citation } \\
\text { Analysis, Policy Impact }\end{array}$ \\
\hline Abstract: & $\begin{array}{l}\text { The case study presented in this paper combines citation and discourse } \\
\text { network analyses to explore entrepreneurial strategies and their long- } \\
\text { term impact on public policy. The analysis draws on and develops } \\
\text { previously published research that documents entrepreneurial influences } \\
\text { on British road policy since the 1980s. Drawing in particular upon } \\
\text { evidence presented in the 2013 Action for Roads White Paper, we } \\
\text { conclude that it is not enough to focus research on a policy } \\
\text { entrepreneur's capacity to mobilize a majority for policy change through } \\
\text { skillful leadership and the strategic use of expertise and social capital to } \\
\text { gain the expected benefits. Studies must also take into account the fact } \\
\text { that once influential individuals may still impact legislation in an advisory } \\
\text { capacity by focusing resources on a particular arena. More importantly, } \\
\text { this strategy can, in the long term, explain why British road policy tends } \\
\text { to remain relatively stable. }\end{array}$ \\
\hline
\end{tabular}

\section{SCHOLARONE Manuscripts}




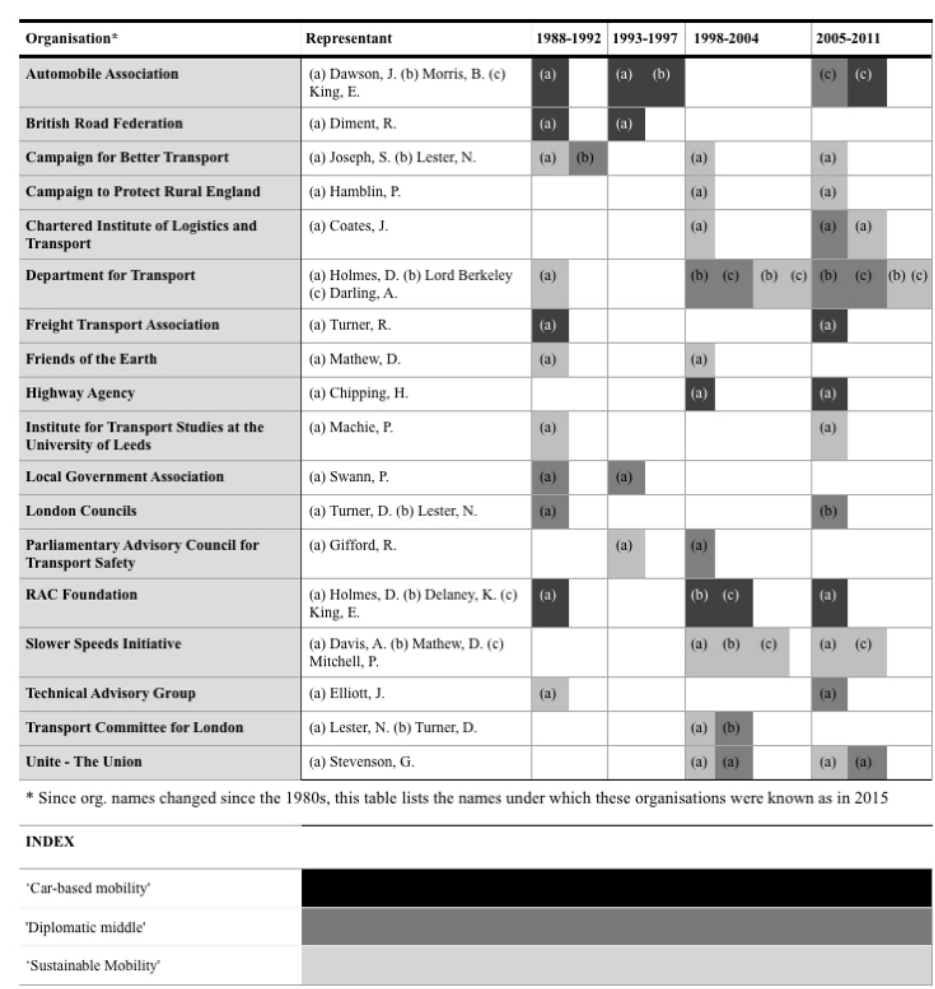

Figure 1

$361 \times 270 \mathrm{~mm}(72 \times 72 \mathrm{DPI})$ 


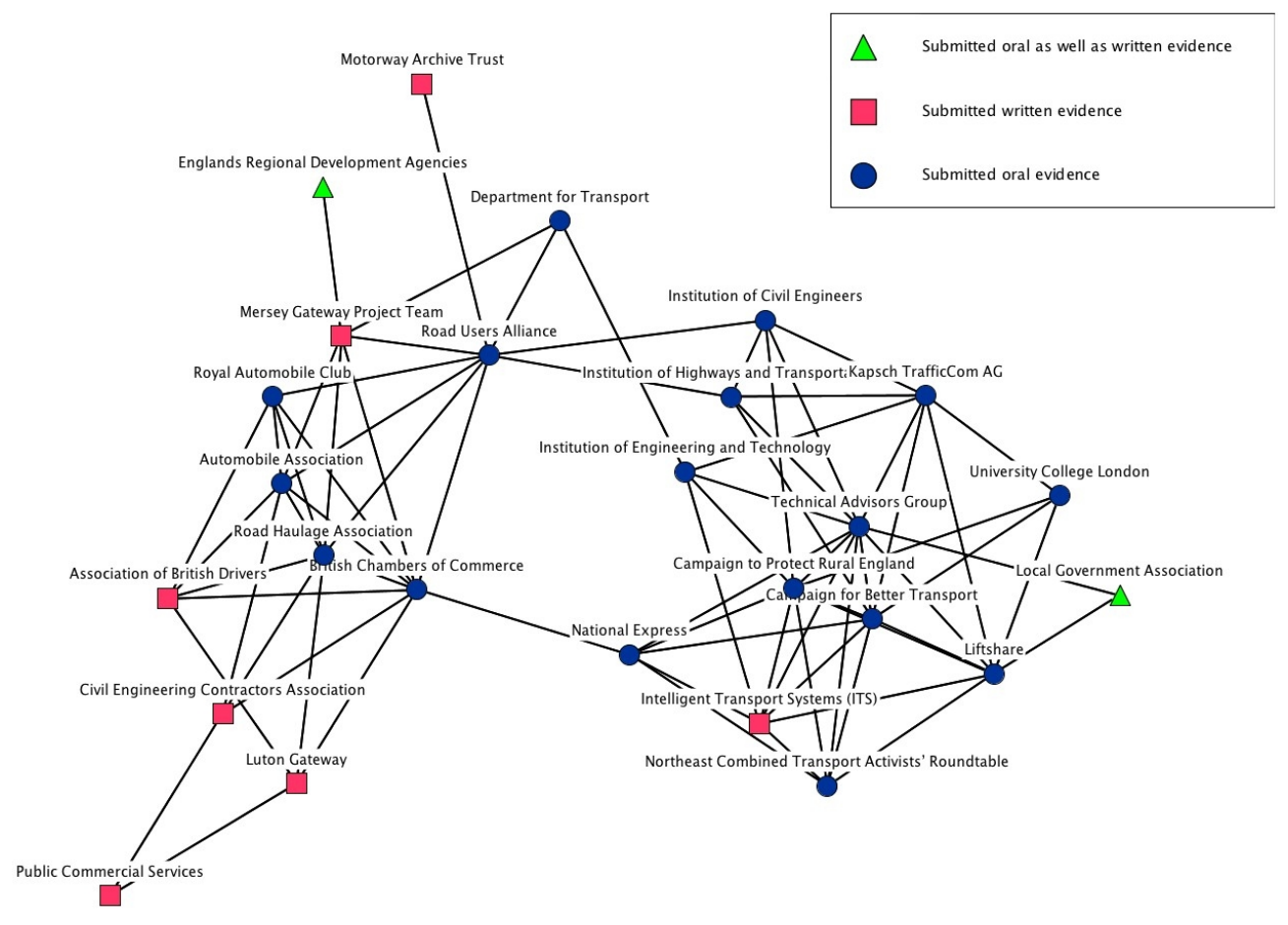

Figure 2

$448 \times 318 \mathrm{~mm}(72 \times 72$ DPI $)$ 


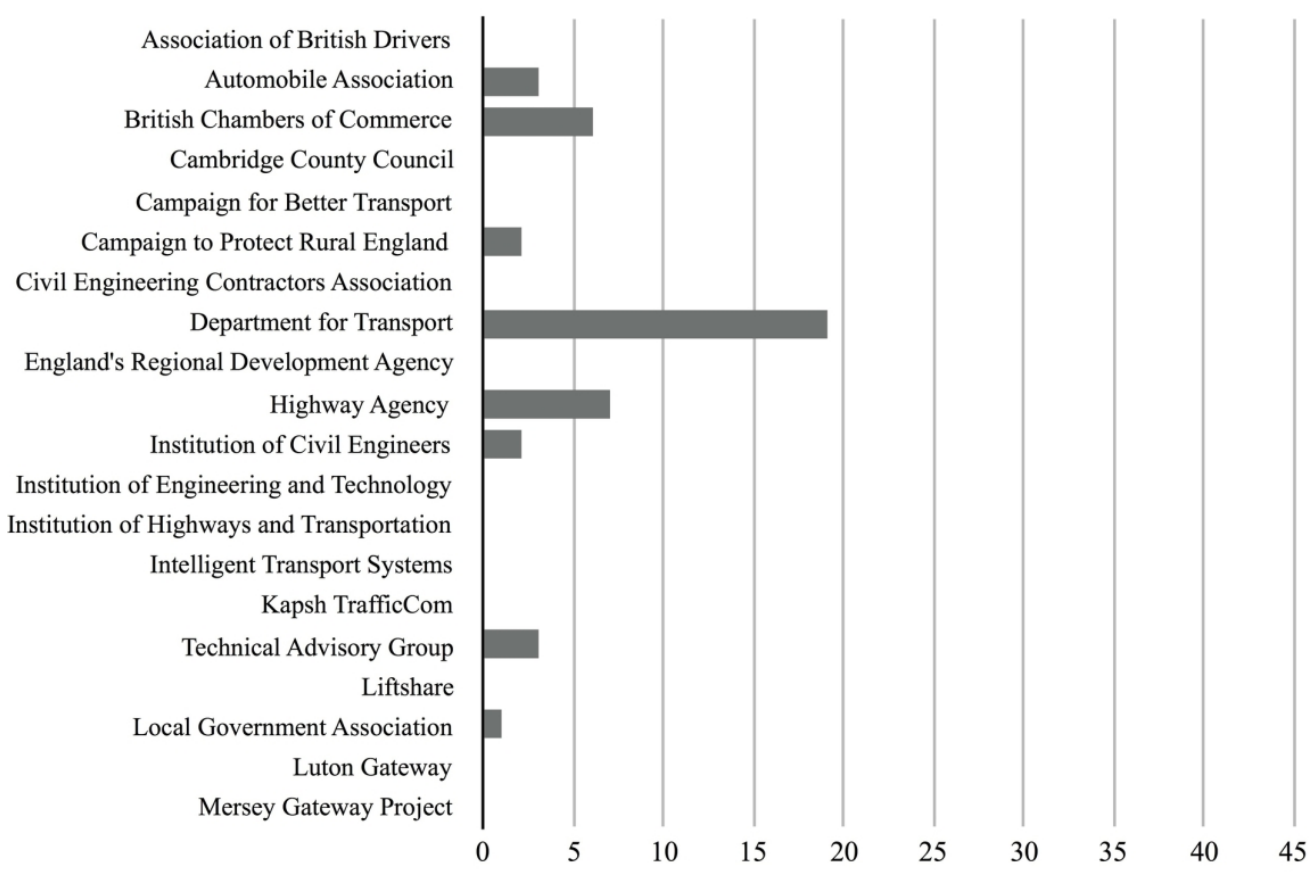

Figure 3

$160 \times 109 \mathrm{~mm}(300 \times 300$ DPI) 


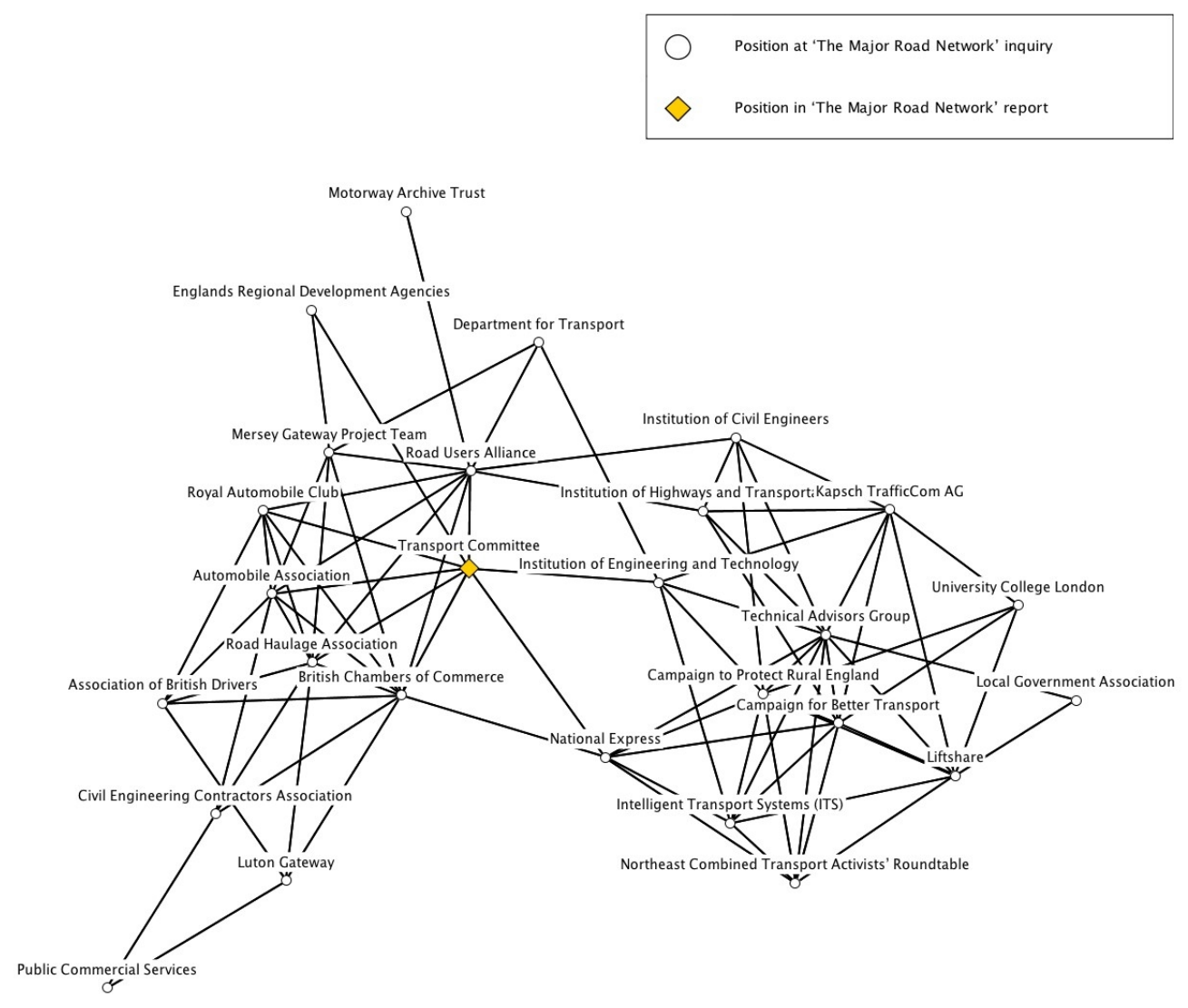

Figure 4

$431 \times 364 \mathrm{~mm}(72 \times 72$ DPI $)$ 


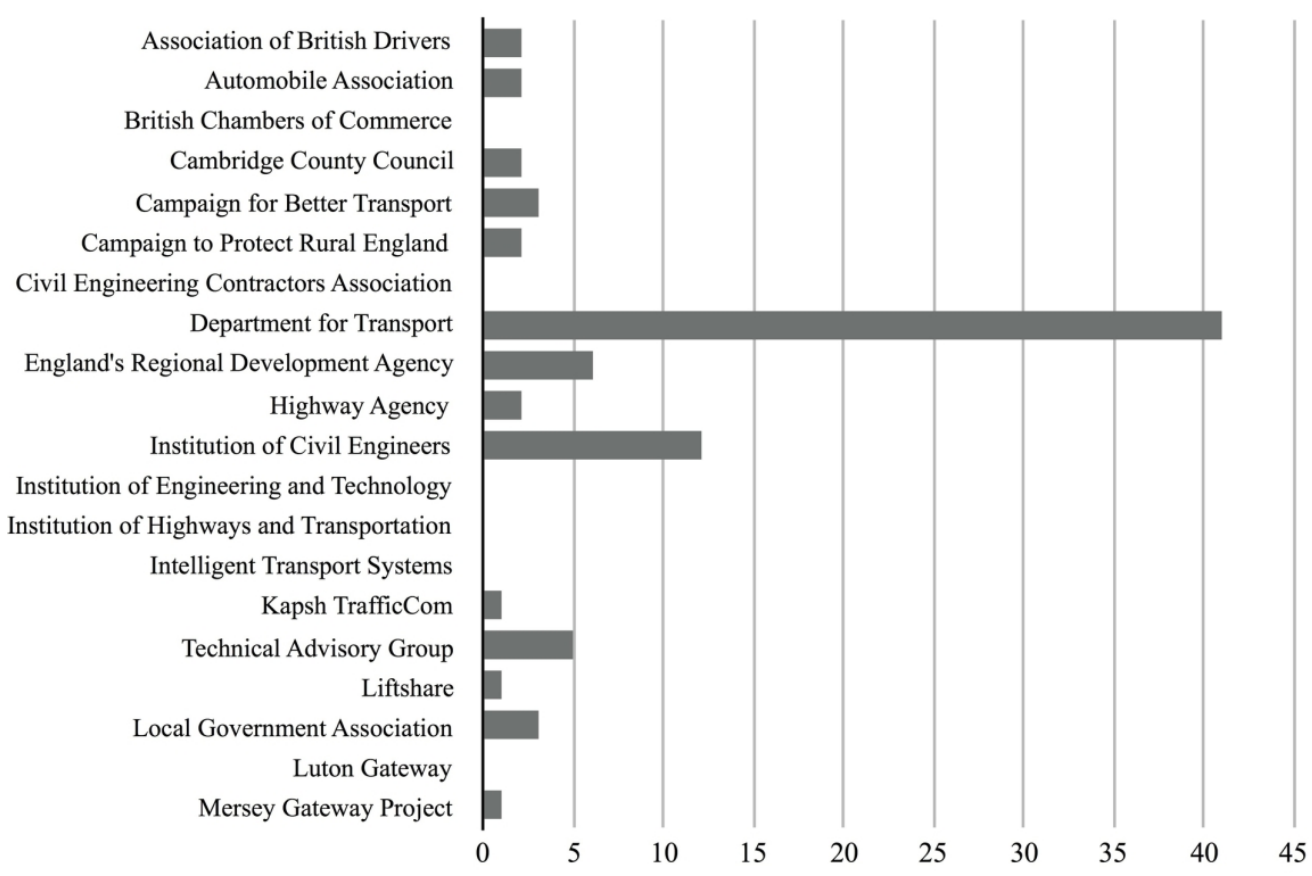

Figure 5

$160 \times 109 \mathrm{~mm}(300 \times 300$ DPI $)$ 
Fully accepted

Partially/ implicitly accepted

Neither nor

Partially/ implicitly rejected Rejected outright

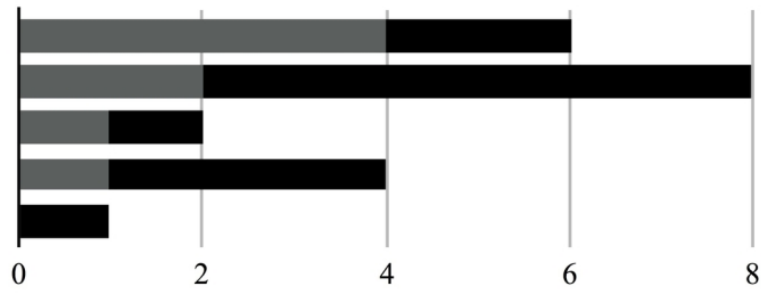

Easy to measure recommendation suggesting medium change to existing government policy Medium to measure recommendation suggesting medium change to existing government policy Impossible to measure recommendation suggesting no change to existing government policy

Impossible to measure/ recommendation suggestion medium change to existing government policy

Figure 6

$150 \times 54 \mathrm{~mm}(300 \times 300 \mathrm{DPI})$ 


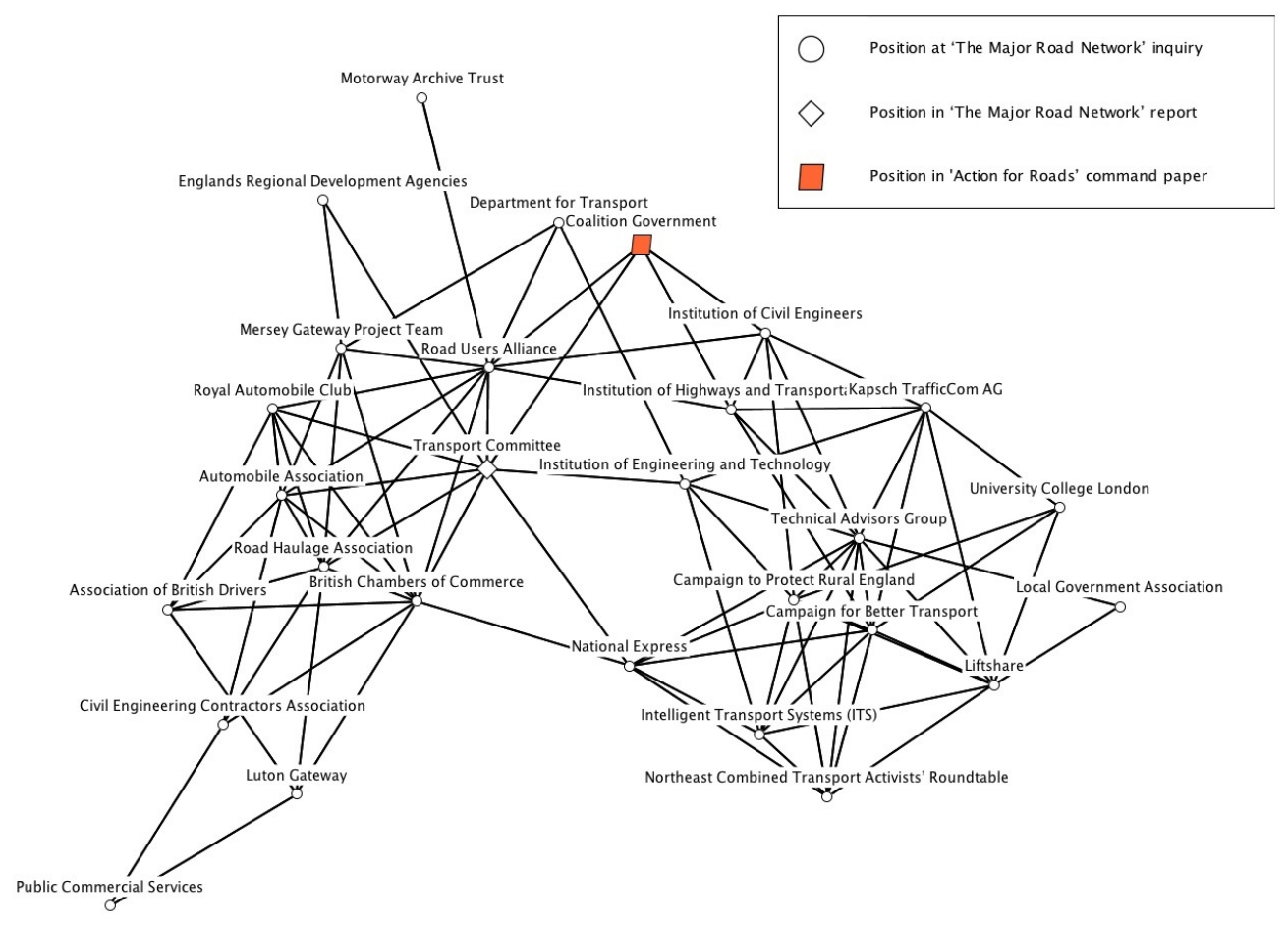

Figure 7

$448 \times 321 \mathrm{~mm}(72 \times 72$ DPI $)$ 


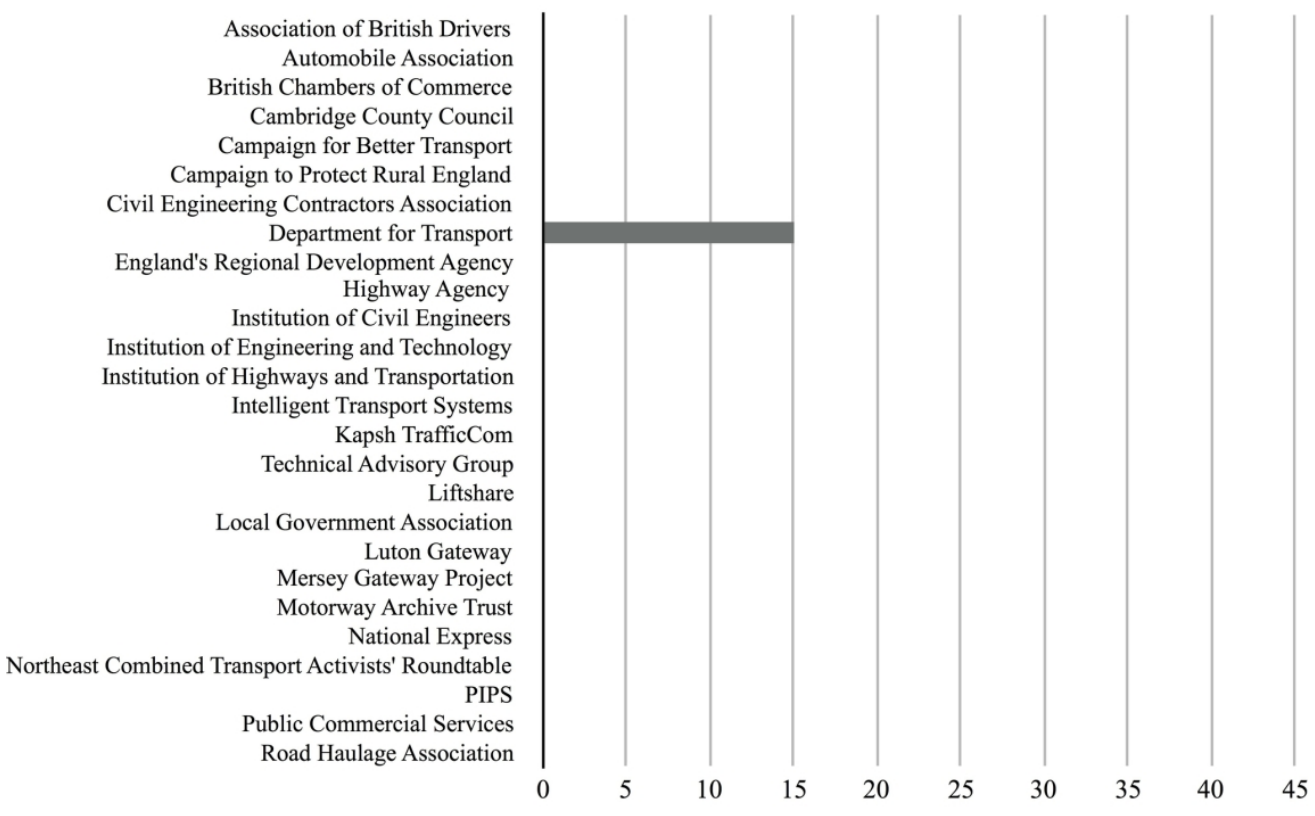

Figure 8

$173 \times 109 \mathrm{~mm}(300 \times 300$ DPI $)$ 


\section{A Long-Term Perspective on Entrepreneurial Strategies and their Impact on British Road Policy}

May 15, 2019

The case study presented in this paper combines citation- and discourse network analyses to explore entrepreneurial strategies and their long-term impact on public policy. The analysis draws on and develops previously published research that documents entrepreneurial influences on British road policy since the 1980s. Drawing in particular upon evidence presented in the 2013 Action for Roads White Paper, we conclude that it is not enough to focus research on a policy entrepreneur's capacity to mobilize a majority for policy change through skillful leadership and the strategic use of expertise and social capital to gain the expected benefits. Studies must also take into account the fact that once influential individuals may still impact legislation in an advisory capacity by focusing resources on a particular arena. More importantly, this strategy can, in the long term, explain why British road policy tends to remain relatively stable.

\section{Introduction}

In the past decade we have seen an increase in studies that explore the proposition that entrepreneurial individuals in and around government control information and facilitate policy change when the opportunity arises (Herweg et al., 2018). The evidence tends to support this claim. The study presented here shows how policy entrepreneurs in the British transport sector that were in no apparent position to influence the direction of policy did so by consistently promoting their expertise in all road-related matters at committee inquiries. What sets the conclusions of this article apart from other observations is that in this case the entrepreneurs that succeeded in the long term were also the individuals that opposed paradigmatic policy change. More common in the literature are case studies in which entrepreneurial activities fundamentally alter the content of policies or programs. Meijerink (2006) offers an example where a group of environmentalists and fisherman successfully exploited scientific evidence and a change in their elected political representation to translate their ideas about coastal flood risk mitigation into legislation. Similar examples can be found in the sectors of health (Lomas, 2007), transport (Dudley \& Richardson, 1996), climate change (Dolan, 2019), environment (Rietig, 2014), defense (Macdonald, 2015) and labor market reforms (Zohlnhöfer, 2016).

Gunn (2017) deduces from these and other examples that policy entrepreneurs may not always be in a position of authority, but their personal traits, experiences and social capital allow them to detect and respond to opportunities and mobilize sufficient support to impact policy formulation. A similar argument is included in Herweg et al., 2018). Building on this argument, the paper presented here explores the differences in entrepreneurial strategies and their long-term impact on policy trajectories. The discussion focuses in particular on entrepreneurial individuals that operate in the context of a national policy subsystem ${ }^{1}$.

The next section locates the research theoretically, followed by an introduction of the analysis. The final section discusses the findings and reflects on challenges and questions for future research.

\footnotetext{
${ }^{1}$ Here, the discussion presented in this paper departs from the research stream that investigates the role of policy entrepreneurs at a supranational or global level; in particular accounts that operationalize the concept of a policy entrepreneur not as an individual but as a collective (see e.g., Nay [2012])
} 


\subsection{Theoretical Foundation}

The discussion utilizes the Multiple Streams Framework to link policy entrepreneurs and their strategies to policy change (Jones et. al., 2016). The underlying assumption is that policy change is the most likely, when entrepreneurs in a policy subsystem successfully identify and exploit political opportunities to successfully promote policies in relation to an immanent problem (Zahariadis, 2014). We focus in particular on the argument that " $t]$ he more successful entrepreneurs are those who have greater access to policymakers" (Zahariadis, 2014: 35).

While an integrated theory of entrepreneurship is still in development (Zahariadis, 2014), we build our discussion on three assumptions deduced from studies that have employed this or a compatible theoretical guide. First, policy entrepreneurs - usually individuals that represent the interests of a particular organization - can capitalize on their personal traits (Gunn, 2017). When directly compared to policy professionals, policy entrepreneurs score higher on creativity, unconventionality, agreeableness and openness to experience. These are traits that are the most effective when combined with an ability to persuade, influence and mobilize others (Timmermans et al., 2014). Second, policy entrepreneurs' knowledge of or experience with a policy issue or process is a necessary, although not sufficient, resource to effectively translate their beliefs into policy narratives (Crow, 2010; Rietig, 2014). These narratives are then communicated to others in an effort to mobilize advocates and collectively develop and promote political strategies (Mintrom \& Norman, 2009). Examples of persuasive narratives can be found in the health and transport sectors, where policy entrepreneurs craft narratives that link policy change to economic prosperity and wellbeing. In doing so, they have been found to be able to mobilize the necessary resources to impact the policy process (see, e.g., Dudley \& Richardson [1996]). Other case studies find that some individuals can offer issue expertise but lack the capacity or time to develop the political knowledge necessary to identify and address the information needs of individuals in positions of authority (Bandola-Gill \& Lyall, 2017; Gunn, 2017). Gollust et al. (2017), for example, show that in the U.S. health sector, policy makers and issue experts lack the time and the mutual trust to engage in evidence-based policy making. Third, policy entrepreneurs rely on both personal traits and persuasive narratives to gain access to and the trust of individuals in positions of authority (Gunn, 2017). Entrepreneurs that have this kind of social capital find it easier to place a policy issue or solution on the political agenda or translate it into legislation (Lomas, 2007). Public policy scholars have already started to map the evolution of these ally networks that form around shared beliefs (see, e.g., Henry [2011], Ingold [2011]), adding weight to observations that policy entrepreneurs nourish narratives that promote the beliefs that glue their coalition together. In this context, policy entrepreneurs form relationships with state officials but also with interest group representatives, journalists, scientists and influential individuals. The available evidence suggests that policy entrepreneurs target in particular authority figures who hold positions of power (Mintrom \& Norman, 2009).

Entrepreneurial activities can lead to fundamental and sustained changes in policy. Through the strategic use of language, networking and policy venues they frame and promote policy solutions to immanent problems (Brouwer, 2015). However, not all entrepreneurs are interested in changing the status quo (Mintrom \& Norman, 2009). Christopoulos (2006) distinguishes incremental from opportunistic strategies. Incrementalists use their capacity and social capital to build a consensus around the status quo and further institutionalize their advisory position. Opportunists have to first draw attention to their expertise, and they exploit windows of opportunity to do so. Both strategies are at play in policy-making contexts. For example, Meijerink (2006) finds that incremental policy entrepreneurs monopolized policy advice on flood defense in the Netherlands for the greater part of the last century. This only changed when opportunistic policy entrepreneurs outside of the political power center were able to exploit changes in government as well as new scientific evidence circulated in related policy subsystems, and successfully attracted support for their innovative narratives. In doing so, they were able to promote their narratives to authority figures and shape policy trajectories 
accordingly. Another example is presented by Dudley and Richardson (1996), whose research explores how policy entrepreneurs have framed and promoted a variety of narratives concerning the nature and resolution of Britain's traffic congestion between 1945 and 1995. Their findings show how one group of policy entrepreneurs successfully framed their belief in unlimited personal mobility (a perspective also termed "predict and provide" (Goodwin et al., 2012)) into a set of narratives that link an increase in road capacity to economic growth and lower levels of air and noise pollution. These "car-based mobility" stories helped them to capture and maintain majority support within the transport policy subsystem for a greater part of the last century, which allowed them to generate sufficient resources to monopolize policy arenas within the Westminster System, and thus define the core elements in British road policy. The result was policy stability. The case study that Dudley and Richardson (1996) present focuses in particular on the late 1980s and early 1990s, when opportunistic policy entrepreneurs of the minority coalition, which advocated mitigating mobility, attempted to attract prospective members from nearby policy subsystems by presenting them with new scientific evidence. They achieved success by utilizing policy venues outside the Westminster System, in particular various media outlets, to promote their belief that car-based mobility must be regulated (a perspective also termed "new realism" (Goodwin et al., 2012)) as a set of "sustainable mobility" narratives linking modal shift to economic growth and lower levels of air and noise pollution. At first these principal actors were only able to attract sufficient support to force minor changes to existing public-spending and road-building plans, but they later expanded their impact with the development of core elements within various regulatory and strategy papers that declared the end of car-based mobility, in particular after the opposition took office. This development suggests that new realism entrepreneurs did in fact manage to infiltrate the advisory system, putting them in the position to influence policy in the long term.

In both cases we find evidence that policy entrepreneurs focused their resources on the brokerage of knowledge, including activities aimed at accessing, narrating and communicating to a person of influence information relevant to policy development or implementation (Bandola-Gill \& Lyall, 2017). The available findings suggest that in each policy subsystem a group of incrementalists, consisting of engineers and planners, monopolized policy advice for the greater part of the last century. At a time when new scientific evidence emerged and a change in political representation seemed likely, opportunists were able to utilize new evidence to mobilize support and effectively challenge the credibility of narratives advocating incremental change. First, they utilized their expertise and personal traits to develop and promote a credible alternative narrative. Second, they build a coalition around this narrative that included individuals running for office. In doing so, they became the opposition's primary source of policy advice. When the opposition took office, this advise was translated into policy with the 1998 "New Deal for Transport" White Paper (Dudley \& Richardson, 2000).

However, policy change was never properly implemented. On the one hand, the financial circumstances before and after the 2008 recession forced advocates to look for alternatives means to fund the intended policy change. On the other hand, the 2000 fuel protests indicated that society at large did not fully support the proposed policy change and was willing to oppose the government on controversial steps, such as road user charging. The window of opportunity eventually closed, when the opponents of the intended policy change regained the majority after the 2010 General Election (Dudley, 2013). Likewise, Botterill (2013) observed how the window of opportunity for changes in the drought policy in the United States closed with a change in administration. The available evidence supports the proposition that the success of entrepreneurial strategies depends not only on the personal traits of the entrepreneurs utilizing them, but also on their experiences and social capital. Access to individuals in positions of authority is a necessary, though not sufficient, condition for a successful entrepreneurial strategy (Gunn, 2017; Herweg et al., 2015). This argument raises the question, what happens when authority figures that were in favor of the status quo reclaim positions of authority? The remainder of this paper outlines an analysis that explores this question, drawing on and 
developing previously published research that documents entrepreneurial influences on British road policy since the 1980s. The following section will introduce the case before detailing and discussing the analysis.

\section{Case Study}

At first glance, British road policy seems an unlikely candidate to attract anyone's attention. However, the readers may be familiar with the "reclaim the street" movement. Some may even know that it originated in Britain, where it was adopted by the anti-road building movement that eventually succeeded in their efforts to shift the public and then the policy discourse away from the then dominant car-based mobility paradigm towards the idea of sustainable mobility. Nevertheless only few policy scholars have been inclined to search for an explanation as to why the underdog seemingly succeeded in this case (see e.g. Witting \& Dudley [2019], Dudley et al. [2018], Dudley \& Richardson [2000]). The available research covered entrepreneurial activities in Britain's transport sector - here in particular decisions about the management and development of the major road network - and has influenced our understanding of entrepreneurial activities and how these impact policy learning and -change (cf. Cairney \& Zahariadis, 2016; True \& Baumgardner, 1999; Sabatier, 1998). What attracted our attention are observations that policy change was never properly implemented (Dudley \& Banister 2018, Dudley \& Richardson 2000). Over time, the apparently defeated coalition rebounded, and was successful in shifting the trajectory of policy back in its favor.

The case was selected as a baseline for this study for this reason, but also for the qualitative data set that Geoffrey Dudley and Jeremy Richardson and their colleagues accumulated about these aspects, covering the period from 1945 until 2013. The research presented in this section focuses on the House of Commons Transport Select Committee ("transport committee" hereafter) meeting minutes and related reports. Witting and Moyson (2015) highlight the transport committee as an open access arena in which representatives of various lobbying groups pursue different strategies to promote a specific set of narratives and subsequently affect policy advice and decisions of central government. The committee specializes in executive oversight. When a committee has to decide on an inquiry, it usually announces this in a press notice which frequently will include an invitation to potential witnesses. Potential witnesses will respond to these invitations and submit written evidence (in the form of a memorandum). Before each inquiry, members receive a brief, including background information and suggested lines of questioning, that committee staff prepare and circulate. Special advisors support the clerk in their role as the head of the committee's staff. The staff works closely with the committee-elected chair ${ }^{2}$ to prepare inquiries as well as inquiry reports. Following an inquiry, the committee, under leadership of the chair, presents the government in office with a set of recommendations. These recommendations are also made available to the general public. The government then published their response. An examination of this process reveals that entrepreneurs exploit committee inquiries to draw public attention to their expertise, influence the committee's recommendations to the government, and affect policy trajectories.

One notable finding of Witting and Moyson's analysis of transport committee sessions is that many witnesses who support sustainable mobility attended only one session, while advocates of car based mobility attended multiple sessions. As defined above (see page 2), individuals that repeatedly lobby the inquiry process can be described as policy entrepreneurs.

\footnotetext{
2 The House of Commons transport committee has been chaired since 1998 by Labour Party representatives, supportive of sustainable mobility. In contrast, the UK government was controlled by various political parties.

The Labour Party held office from 1997 to 2010, after which a coalition government (Conservative and Liberal Democrat) took power, followed by a Conservative government in 2015 .
} 
Figure 1 details the content contributed by policy entrepreneurs that participated in at least two transport committee inquiry sessions in Witting and Moyson's case study. The analysis of their oral statements suggests that a small group of entrepreneurs persistently advocated the car-based mobility narratives at every road-related committee inquiry, whereas a loosely integrated set of entrepreneurs from environmental organizations and local groups opposed to controversial road schemes targeted individual inquiries to advocate sustainable mobility. The darkest shade denotes statements supporting car-based mobility. The lightest shade indicates statements advocating sustainable mobility, whereas grey labels represent a middle ground position. It captures instances in which individuals express support for each of the two opposing perspectives during one inquiry - defined here as "diplomatic middle". With the exception of one person (Holmes, D.), none of the observed entrepreneurs radically diverted from either set of narratives when giving evidence to the transport committee, despite varying inquiry topics and opportunities to target a different set of supporters (see Supplementary Material Doc 1).

Whereas in the 1980s and early 1990s the majority of transport committee inquiries addressed roadrelated policies and plans, in the mid-1990s inquiries primarily focused on road traffic regulation (Witting and Moyson, 2015). This shift reflects a shift in public opinion in favor of sustainable mobility (see, e.g., Banister [2008], Dudley [2013]).

These observations suggest that through skillful leadership, entrepreneurs on each site tried to control policy advice and subsequent policy formulation in different ways. Although the car based mobility advocates had apparently found their public support and policy influence reduced, by persistently targeting the select committee arena to advocate their set of narratives they maintained strong political connections within the Westminster System. Furthermore, this strategy allowed them to maintain the trust in their expertise on transport-related matters - Trust established during the time when they monopolized transport policy advice. In contrast, sustainable mobility advocates continued to pursue a more disparate and media-focused brokerage strategy (which can be labeled as opportunistic) designed to maintain their loosely integrated alliance and consequent agenda control. This approach was focused on brokering knowledge between a diverse set of environmental groups, and it benefited from the short-term involvement of scientific experts (see, e.g., Banister [2008], Dudley [2013]). Each strategy was put to a test when the transport committee decided to review current road policy one year before the 2010 General Election, when it was already predicted that Labour might lose office.

Fig. 1: Content of Oral Witness Statements by Organization

\subsection{Methodology}

This section introduces a mixed-method case study that further develops the analytical framework above, and addresses the question, what happens when authority figures that were in favor of the status quo reclaim positions of authority? The study focused on archival records and employed citation analyses (capturing whose expertise is cited) with a discourse network analysis (linking actors [individuals' names and organizational affiliation at the time ${ }^{3}$ ] to narratives). It was designed to capture the actors involved in promoting specific narratives to the select committee and relate their recommendations to government policy. In addition, Benton and Russell's (2011) approach and an

\footnotetext{
${ }^{3}$ In our presentation of the analysis we only state the individual's organizational affiliation.
} 
article count was used to also capture the impact of the Committee's recommendations on the government's response and provide some background to the analysis.

Data collection involved two independent coders manually tracing the flow of information from the input that policy entrepreneurs provide at transport committee sessions to policy output. More precisely, the study investigates four interconnected stages of this process. First, it analyses the evidence that policy entrepreneurs submitted to the transport committee in the context of their inquiry into the major road network, conducted May-July 2009 and summarized in the report, The Major Road Network: Eight Report of Session 2009-10 (HC 505, March 2010). Second, the study investigates whose evidence was incorporated into the report. Third, it examines how the coalition government that was elected in May 2010 responded to the list of recommendations outlined in the aforementioned report. Here the analysis focuses on 'The Major Road Network: Government Response to the Committee's Eighth Report of Session 2009-10' (HC421, published in July 2010). Finally, the study analyzes the Command Paper, Action for Roads (July 2013) (in which the newly elected government outlined for the first time its road policy plans) to evaluate how many of the recommendations were translated into policy.

\subsection{Analysis}

The remainder of this paper will introduce each stage of our analysis separately, followed by a discussion of the remaining challenges and questions.

\section{Impact on the The Major Road Network inquiry (May-July 2009)}

First, we analyzed the content of the written and oral evidence that the transport committee received prior to or during the 2009 inquiry was analyzed. The analysis used the Leifeld Discourse Network Analyzer, which was applied, which combines qualitative content analysis and quantitative social network analysis. This approach was considered to be the most appropriate tool for this project, as it has recently been successfully employed in record-based advocacy coalition research, and was considered to be the most appropriate choice for this project (see, e.g., Leifeld [2013]; Rinscheid [2015]). The data was manually collected from the meeting transcripts attached to the Major Road Network report, published in July 2010. The discourse network analysis focused on the content of the written statements and, where no such statements were submitted, on the content of the oral evidence given to the transport committee during the inquiry. All statements were coded into ten categories, where each category constitutes a narrative corresponding to one of the ten questions raised by the transport committee in their call for evidence. First, the name of the person or organization giving evidence was recorded. Second, for each of the ten categories a dichotomous variable was created, indicating either agreement or disagreement. As one example, the transport committee asked the question: "Is the current major road network adequate for the needs of the UK economy and for individuals?"

Answers to this question were inductively developed from the available evidence, and related to one of two possible answers in Category 1, "Capacity Current Road Network":

Yes, the coverage and capacity of the major road network is adequate for the needs of the UK economy and for individuals.

No, the coverage and capacity of the major road network is inadequate for the needs of the UK economy and for individuals.

The discourse network analysis identified co-occurrences in the evidence. The data was then imported into UCINET 6 in order to conduct the Johnson Hierarchical Cluster analysis identifying nested 
partitions within the network. The algorithm used in this context calculated the distance between the clusters as the average similarity value weighted, identifying degrees of association (similarity) among the organizations within the cluster; in other words, the levels at which clusters become visible.

The analysis shows that a total of twenty-nine organizations submitted and/or gave evidence in the context of the major road network inquiry. Figure 2 summarizes the discourse network analysis of their evidence, clustering co-occurrences at and above 0.5496 degree of association (similarity). At this level the discourse network starts to clearly break into two clusters. Three of the twenty-nine organizations are not shown in the graph, due to missing data concerning their position on the transport committee's questions. In the case of the Highway Agency and Cambridgeshire County Council, who only gave oral evidence, data is missing due to the nature of the questions. In contrast, data is missing for PIPS Technology Ltd, an industry leader in the development and manufacture of Automatic Number Plate Recognition systems, because POPS narrowly focused their evidence on addressing the tenth question concerning the potential of technological innovations. Most organizations submitted both oral and written evidence (denoted as circles), a few submitted only written evidence (denoted as squares), and even fewer gave only oral evidence (denoted as triangles).

A closer analysis of the discourse network presented in Figure 2 shows that the membership in each cluster corresponds with the coalition membership that previous research identified (Dudley and Richardson 2000). Organizations in the larger cluster on the right side of the discourse network promoted the view that while the coverage and capacity of the major road network is adequate for the needs of the UK economy and for individuals now and in the future, the network will have to be better managed to avoid congestion. This corresponds with the set of sustainable mobility narratives linking improved road regulation to economic growth and improved air and noise pollution. This cluster includes the Campaign for Better Transport and the Campaign to Protect Rural England. On the left side of the network seen in Figure 2, we find known advocates of car-based mobility, such as the Royal Automobile Club and the Road Haulage Association. Contrary to opposing groups, these organizations argue that the current capacity of the major road network is insufficient, that modal shift cannot solve the issue, and that transport planning and land-use planning have the potential to address only minor aspects of this overall problem. Several organizations at the periphery of each cluster, among them the Department for Transport, adopt an in-between position, arguing that some parts of the road network need increased capacity to solve congestion problems at peak times when it becomes clear that modal shift, travel planning, and land-use planning cannot tackle the problem alone. A small cluster promoting car-based mobility notwithstanding, the sustainable mobility narrative is more strongly represented in this discourse.

Following the analysis of the written and oral discourse, citations recorded in the minutes of oral evidence during the major road network inquiry (HC505) were analyzed to establish whose evidence dominated the discussion. Here the analysts first identified sentences in the source material containing cue words, such as "I" and "read", and a noun-phrase marking a specific organization. Second, the cited source in the sentence was recorded. Where no such information was available, or where the identity of the cited source was unclear, the sentence was coded as "non-citation". Finally, the citer's name was recorded (Witting, 2015).

The results of the citation analysis are presented in Figure 2, and suggest that the evidence presented by the Royal Automobile Club and the Department for Transport were most often discussed, indicating that their narratives are most likely to be transferred to the subsequent transport committee report discussed below. The evidence presented by the Royal Automobile Club included in-house research on traffic growth, distance-based charging, and the expansion of the road and rail network. Former special advisor Stephen Glaister (who has advocated car-based mobility first as an academic and latter as the director of the Royal Automobile Club) was involved in conducting this research. 
Evidence presented by the Department for Transport included in-house traffic forecasts up to 2025, the national travel survey and local sustainable travel studies.

On a side note, the analysis brings to attention evidence not directly presented to the committee (and thus not shown in Figure 2), in particular that presented in the Eddington Review, co-sponsored by the Treasury and the Department for Transport, which stresses the importance of a cost-effective and economically beneficial mixed-modal solution that focuses on small transport schemes. While the report was utilized by representatives of the Department for Transport to make a case against largescale road building, it was used by the Royal Automobile Club to challenge the government's High Speed Rail plans and to highlight the importance of small projects that would increase the road capacity at congestion hotspots.

Fig. 2: Discourse network (left), and evidence promoted at the 2009 Major Road Network inquiry (right)

\section{Impact on the The Major Road Network report (March 2010)}

Second, we analyzed the content and citations recorded in the 2010 report, The Major Road Network (HC505). Our aim was to establish whose ideas the transport committee adopted and translated into recommendations for the government. According to the minutes attached to this report, all committee members except Sir Peter Soulsby (observed to have argued in this context in favor of car-based mobility, ibid: Q140) supported the wording of this report.

The same approach and coding scheme as used as above was employed to analyze the content of the 2010 report, and locate the transport committee within the discourse network outlined in Figure 2. The findings are presented in Figure 3. Like the Department for Transport, the transport committee positioned itself at the edge of the car-based mobility cluster (left side of the discourse network); advocating small road-building schemes in preference to larger road building projects and High Speed Rail.

In order to also examine citations in the report's text, the analysis followed the examples of Ledermann (2014) and McAllister et al. (2014). The findings are presented in Figure 3. Although the discussion leans heavily on evidence provided by the Department for Transport, it cites organizations in the car-based mobility coalition more often than advocates of sustainable mobility, despite the latter being more strongly represented in the actual evidence submitted to the transport committee in 2009. The most discussed sources of information in this context were the statements by Stephen Glaister (of the Royal Automobile Club) to the transport committee on the 24th of June, 2009, and various statements and materials published by representatives of the Department for Transport.

Fig. 3: Position in discourse network (left), and evidence promoted in the 2010 Major Road Network report (Right) 
In Britain, select committees are generally well regarded in terms of their influence on the policies of central government (Benton \& Russell, 2011). The transport committee, under the charismatic leadership of Gwyneth Dunwoody (1997-2008) and Louise Ellmann (2008-2017), frequently attracted the attention of the public and the executive. However, the attention varied with the issues that were deliberated. The Major Road Network report was nationally featured only in The Telegraph (which ran the story under the headline "More motorways and 900 miles of trunk roads needed, say MPs" (30th March 2010)), which raises doubts about its capacity to shape British road policy. Because of this observation, the impact of the report was assessed in a third phase of our analysis. For this analysis, each of the twenty-three recommendations listed in the committee's Major Road Network report were ranked in terms of their measurability and recommended level of "policy alteration," adopting the coding scheme used by Benton and Russell in their 2011 study. The latter term captures the extent to which a committee recommendation seeks to reverse existing government policy. This was coded on a three-point scale:

(a) No change or only small change to government policy.

(b) Medium change to government policy (including 'recommendations which go further, but fall short of a reversal or near-reversal', for example, by calling for new action significantly different in terms of policy direction, priority or resources, or calling for exploration in areas where policy does not currently exist).

(c) Large change or complete reversal of government policy (including 'recommendations which very significantly deviate from current policy', e.g., shutting down programs, dropping targets, ending funding, or adopting new action in clear conflict with existing policy direction).

Measurability, on the other hand, captures "the extent to which it would be possible to determine whether a recommendation was successful, if we were in possession of perfect information". In our analysis this took three values:

(a) Easy to measure (for example, the recommendation set clear targets and deadlines).

(b) Medium measurability (essentially a middling code between 1 and 3).

(c) Virtually or entirely impossible to measure ('recommendations which are vague, unspecific, phrased in general terms', etc., or where no objective assessment would be possible).

We then assessed the extent to which these recommendations were accepted by the government in its written response to the committee's report. Following Benton and Russell (2011), a five-point likert scale was used, distinguishing:

(a) Fully accepted (i.e. explicit full acceptance).

(b) Partially or implicitly accepted (including implicitly accepted, part accepted but part ignored, or currently being carried out but begun after the start of the committee's inquiry).

(c) Neither accepted nor rejected (including part accepted but part rejected, under consideration, refusal to respond for reasons of security, or a claim that the action was being carried out with no indication of when it started).

(d) Partially or implicitly rejected (including part rejected but part ignored, implicitly rejected, ignored or dodged, or a claim that the action was being carried out with a clear implication that the committee was mistaken in believing that change was needed). 
(e) Rejected outright (i.e. explicit full rejection).

Our analysis presented in Figure 4 shows that the vast majority of the committee's twenty-three recommendations call for no, or hardly any, change to government policy, and cannot easily be evaluated in terms of determining whether a recommendation was successfully translated into policy. Furthermore, the findings highlight that the coalition government that took office only a few weeks after the recommendations were published fully or partially accepted the recommendations with reference to its Coalition Agreement and ongoing work. In their response they committed to investing in additional capacity and to using technological innovations in order to de-carbonize and better manage Britain's road infrastructure, they also committed to cutting public spending in response to the recent economic recession. The transport committee's recommendations were partially or outrightly rejected when they were regarded as financially unfeasible or entirely unfounded, such as the claim that the coalition government was unable to aggregate traffic growth predictions (Paragraph 74). In response to the latter, the government replied (HC421: 8):

The Department's forecasts for road traffic produced by the National Transport Model do take account of the trip rates and purposes for different age groups, and how these will be affected by a changing future population structure.

Given that the transport committee, upon deliberation and publication of these recommendations in March 2010, could not have foreseen the general election outcome in May 2010, it seems unlikely that the content of the report was framed to fit a specific government program. However, one cannot rule out that a newly formed coalition government would at this stage of their time in office carefully word any public response to a select committee to promote their agenda for the years ahead. The lack of measurable recommendations raises doubts as to whether these ideas transferred into policy actions. Nevertheless, the committee was known to arrange follow-up inquiries and attract public attention (largely due to the charismatic leadership of Gwyneth Dunwoody up until 2008), a practice which according to Benton and Russell (2013) can be a threat and in this case may have provided sufficient pressure to motivate the coalition government to at least give the impression of acting upon these recommendations (ibid: 788).

Fig. 4: Government acceptance of transport committee recommendations (count by type)

\section{Impact on the coalition government's Action for Roads command paper (July 2013)}

For the final stage of her analysis, we analyzed the content of the coalition government's Action for Roads command paper (Cm. 8679, prepared by the Department for Transport and Highway Agency, and published in July 2013), employing the same approach and coding scheme as above, to locate the coalition government's position within the overall discourse network. The report followed upon the June 2013 Spending Review in which the Treasury announced "the biggest road investment in half a century". It was the first command paper to outline the government's vision for road policy that was published after its response (HC421) to the committee's The Major Road Network report (HC505). Figure 5 presents the findings of the analysis, which locates the views expressed in the command paper between the two opposing clusters identified in this discourse network.

The analysis of citations within this document is presented in Figure 5. Findings challenge the idea that the coalition government sits between the two competing advocacy coalitions. The small number 
of citations included in the text are asymmetrically distributed between the Department for Transport and the Royal Automobile Club. The latter was only cited once, to highlight growing demand for the strategic road network, whereas various Department figures were cited in the text a total of nine times. Most heavily and consistently referenced was the Department for Transport commissioned A Fresh Start for the Strategic Road Network report. It was cited in six different contexts within the command paper. The report was prepared by Alan Cook in 2011. The authorship involved some of the policy entrepreneurs who submitted evidence to the transport committee in 2009, including the British Chamber of Commerce, the Royal Automobile Club, the Chartered Institution of Highways and Transportation, and the Campaign to Protect Rural England (Cook, 2011). With the exception of the Campaign to Protect Rural England, all of these organizations were advocates of car-based mobility, implying that this discourse was shifting toward this narrative. In other words, the persistence with which roads advocates targeted the select committee to reassert their advisory status within the Westminster System was finally beginning to pay off.

Fig. 5: Position in discourse network (left), and evidence promoted in the 2013 Action for Roads command paper (right)

\subsection{Discussion}

In this section we explore the question, what happens when authority figures that were in favor of the status quo reclaim positions of authority? Firstly, the research supports the suggestion that the set of car-based mobility narratives entrepreneurs advocate has not changed since the 1980s (see e.g., Witting \& Moyson [2015]). The narrative can be summarized in the words of the most often cited entrepreneur in this cluster, Stephen Glaister of the Royal Automobile Club, who is quoted in the national newspaper, The Telegraph, as saying:

More than nine out of ten passenger journeys take place on the roads and with large population and traffic growth forecast for the years ahead some sensible form of road building is essential to keeping Britain moving (...) This is not about concreting over the country, but accepting that roads are vital to the economic and social wellbeing of the nation (. . . ) After all the hype about high speed rail at last some politicians have recognized the reality of most people's daily lives (The Telegraph, 30th March 2010).

Secondly, the research highlights that opportunistic entrepreneurs supporting sustainable mobility, such as Stephen Joseph (of the Campaign for Better Transport) and Ralph Smyth (of the Campaign for the Protection of Rural England), dominated the transport committee's major road network inquiry in 2009. In contrast, fewer car-based mobility supporters were heard in this context, but their ideas nevertheless were well represented in the subsequent report.

Finally, the 2013 command paper may have been phrased in a diplomatic manner so as to appear neutral, but it is primarily grounded on evidence that has emerged from the car-based mobility cluster. These findings support the conclusion that sustainable mobility had a strong voice at the 2009 transport committee hearings, but that this support did not transfer into the 2010 committee report nor the 2013 command paper. While it may well be that the car-based mobility cluster has lost public support and is less well represented at transport committee hearings, it remains relevant as long as entrepreneurs manage to translate their shared belief in predict and provide into policy whenever the opportunity presents itself. The key to their ability to impact legislation despite possessing minority support seems to be a narrow entrepreneurial strategy focused on promoting their expertise on all 
road transport-related matters to information brokers (such as the committee) at the heart of the Westminster System.

\section{Challenges and questions for future research}

The research shows that entrepreneurs strategically manage relationships by carefully targeting their resources at venues that promises the greatest return (Brouwer, 2015). We find evidence that confirms the statement that successful entrepreneurs have access to policymakers (Zahariadis, 2014). However, the study also shows that not all entrepreneurial activities are driven by the desire to change policy (Mintrom \& Norman, 2009). To the contrary, entrepreneurial activities can also be designed to slow down or prevent rapid policy change. These activities can be seen an attempt to protect their footprint in the governance structure for as long as it takes to regain control. This incremental strategy requires not only issue expertise, but also extensive knowledge of the policy process. Such an expertise is accumulated over time. Scholars currently assume conditions under which opportunistic entrepreneurs run short of time to influence a particular policy decision before a window of opportunity closes (Bandola-Gill \& Lyall, 2017; Gunn, 2017). This study confirms their observations and moves the spotlight at activities of incremental entrepreneurs that at the same time use their extensive knowledge of the policy process and established relationships to prevent rapid changes.

The multiple streams framework emphasizes the importance of the opportunistic role played by entrepreneurs in opening policy windows, but entrepreneurs that play a longer and more patient game can also be extremely significant. Thus a policy window may appear to have closed when policy change takes place, but this does not guarantee that policies will be carried through to full implementation over time. External events, such as elections and changes in financial circumstances, can be vital, and persistent entrepreneurs can take advantage of these to shift the trajectories of policies back in their favor. The entrepreneurs can also take circumstances into their own hands, by persistently targeting key arenas in order to influence ministers and their officials.

More specifically, in the context of British road policy, the research confirms that the strategy employed by opportunistic entrepreneurs to increase public support and subsequently force the Westminster System into agreement initially paid off, and the sustainable mobility narrative dominated the political agenda throughout the 1990s and 2000s. It also shows that their initial approach to target the public and externalize the conflict has remained consistent until the present (Witting \& Moyson, 2015). This strategy has resulted in an increased presence of sustainable mobility entrepreneurs at committee inquiries. Furthermore, the analysis presented in this paper suggests that the sheer persistence of the roads advocates, and their determination to keep promoting the same advice over time through experts with strong ties to the select committee (e.g. Stephen Glaister) paid off in the end in the form of the 2013 Action for Roads command paper.

These observations suggest that when entrepreneurs took the limelight to promote new realism, they did not replace the community of advisors advocating predict and provide who had held power since 1945. Rather, what used to be a community dominated by only one group now involves a diverse cast. In this new context, the old guard that advocated predict and provide seems to know where to find the strings and when to pull them for the best effect. Thus, this study confirms Gunn's findings (2017) that social capital is a necessary but not sufficient condition to successfully promote a particular narrative. Neither are personal traits and issue expertise. Entrepreneurs that possess each of these assets but also score high on knowledge of the policy process are the most likely to maintain control over policy advice and policy formulation.

The findings of this study also raise challenges and questions for future research, in particular with regards to the role of opportunistic entrepreneurs in mature policy subsystems. Yes, they may, during a rare window of opportunity, affect policy formulation. However, the evidence implies that they lack 
sufficient political knowledge and contacts to sustain this change. Could it be possible that their primary purpose in a mature policy subsystem is to force an epistemic community with highly specialized knowledge to recognize and deliberate innovative solutions to fairly consistent policy problems, as seemed to have been the case in Britain where politicians have struggled with an increased demand for a fast and reliable -yet affordable- transport system since 1945?

Before we can answer these fundamental questions, we need to understand, why the sustainable mobility advocates did not change their political strategy after they had gained majority support (e.g., promote and institutionalize their advisory capacity within the Westminster System through former special advisors to the select committee)? What resources do incremental entrepreneurs employ to maintain control over policy advice? What resources do they activate to regain control? What are the conditions under which such an attempt would be made? These remain open questions for now, since the field lacks research that covers the continued development of entrepreneurial strategies in a subsystem context. In addition, it lacks research that traces different narratives from the moment they enter the policy process until policy output. The research presented here is a first step forward in addressing this research gap.

A related challenge concerning the operationalization of these questions has emerged in this context. The qualitative research that has informed this discussion is resource intensive, and less generalizable. In contrast, more quantitative studies tend to focus on empirically observable processes, and thus lack the sufficient depth. The most effective research method seems to lie somewhere in between these two approaches. Recommended case study designs will integrate qualitative and quantitative methods to capture different aspects of the process and develop theories from the aggregate findings. We thus encourage researchers to employ these recommendations and further develop the research presented here.

\section{References}

Bandola-Gill, J. and Lyall, C. (2017). Knowledge Brokers and Policy Advice in Policy Formulation. In Howlett, M. and Mukherjee, I., editors, Handbook of Policy Formulation, chapter 15, pages 249264. Elgar Publishing.

Banister, D. (2008). The sustainable mobility paradigm. Transport Policy, 15 (2): 73-80.

Brouwer, S. (2015). Policy Entrepreneurs in Water Governance: Strategies for Change. Heudelberg, New York, London: Springer, pp. 23-65

Botterill, L.C. (2013). Are Policy Entrepreneurs Really Decisive in Achieving Policy Change? Drought Policy in the USA and Australia. Australian Journal of Politics and History, 59 (1): 97-112.

Cairney, P. and Zahariadis, N. (2016). Multiple streams approach: A flexible metaphor presents an opportunity to operationalize agenda-setting processes. In Zahariadis, N., editor, Handbook of Public Policy Agenda Setting, chapter 6, pages 87-105. Cheltenham, UK: Edward Elgar Publishing Limited.

Christopoulos, D.C. (2006). Relational attributes of political entrepreneurs: a network perspective. Journal of European Public Policy, 13 (5): 757-778.

Crow, D.A. (2010). Policy Entrepreneurs, Issue Experts, and Water Rights Policy Change in Colorado. Review of Policy Research, 27 (3): 299-315.

Dolan, D.A. (2019). Multiple Partial Coupling in the Multiple Streams Framework: The Case of Extreme Weather and Climate Change Adaptation. Policy Studies Journal (online). 
Dudley, G. (2013). Why do ideas succeed and fail over time? The role of narratives in policy windows and the case of the London congestion charge. Journal of European Public Policy, 20 (8):1139-1156.

Dudley, G. (2003). 'Ideas, Bargaining and Flexible Policy Communities: Policy Change and the Case of the Oxford Transport Strategy', Public Administration, 81 (3): 433-58.

Dudley, G. and Banister, D. (2018). Expertise in decision-making for large insfrastructure projects: from UK trunk roads to High Speed Rail 2. Transportation Planning and Technology, 41 (5): 481496.

Dudley, G. and Richardson, J. (2000). Why Does Policy Change? Lessons From British Transport Policy 1945-99. London: Routledge.

Dudley, G. and Richardson, J. (1996). Why does policy change over time? Adversarial policy communities, alternative policy arenas and British trunk roads policy 1945-95.

Gollust, S.E., Seymour, J.W., Pany, M.J., Goss, A., Meisel, Z.F., and Grande, D. (2017). Mutual distrust: Perspectives from researchers and policy makers on the research to policy gap in 2013 and recommendations for the future. Inquiry (United States), 54.

Goodwin, P., Hallett, S., Kenny, F., and Stokes, G. (2012). Transport: The New Realism. Gunn, A. (2017). Policy entrepreneurs and policy formulation. In Howlett, M. and Mukherjee, I., editors, Handbook of Policy Formulation, chapter 16, pages 265-284. Elgar Publishing.

Henry, A.D. (2011). Ideology, power, and the structure of policy networks. 39 (3): 361-384.

Herweg, N., Zahariadis, N. and Zohlhöfer, R. (2018). The Multiple Streams Framework: Foundations, Refinements, and Empirical Applications. In: Weible, C.M., Sabatier, P.A., editors. Theories of the Policy Process, chapter 1, pages 25-58. Boulder, CO: Westview Press, 4th edition.

Herweg, N., Huß, C. and Zohlnhöfer, R. (2015). Straightening the three streams: Theorising extensions of the multiple streams framework. European Journal of Political Research 54: 435-449.

Ingold, K. (2011). Network structures within policy processes: Coalitions, power, and brokerage in swiss climate policy. Policy Studies Journal, 39 (3): 435-459.

Jones, M.D., Peterson, H.J., Pierce, J.J., Herweg, N., Bernal, A., Raney, H.L., and Zahariadis, N. (2016). A River Runs Through It: A Multiple Streams Meta- Review. Policy Studies Journal 14 (1): $13-36$.

Kingdon, J.W. (2010). Agendas, alternatives, and public policies (2nd Edition). HarperCollins Publishers.

Lomas, J. (2007). The in-between world of knowledge brokering. Bmj, 334 (7585): 129-132.

Macdonald, J.M. (2015). Eisenhower's scientists: Policy entrepreneurs and the test-ban debate 1954-1958. Foreign Policy Analysis, 11(1): 1-21. 
Meijerink, S. (2006). Journal of European Public Understanding policy stability and change . the interplay of advocacy coalitions and epistemic communities, windows of opportunity, and Dutch coastal flooding policy. Journal of European Public Policy, 12 (6): 1060-1077.

Mintrom, M. and Norman, P. (2009). Policy entrepreneurship and policy change. Policy Studies Journal, 37 (4): 649-667.

Nay, O. (2012). How do policy ideas spread among international administrations? Policy entrepreneurs and bureaucratic influence in the un response to AIDS. Journal of Public Policy, 32(1): $53-76$.

Rietig, K. (2014). 'Neutral' experts? How input of scientific expertise matters in international environmental negotiations. Policy Sciences, 47 (2): 141-160.

Sabatier, P.A. (1998). The advocacy coalition framework: revisions and relevance for Europe. Journal of European Public Policy, 5 (1): 98-130.

Timmermans, J., Van Der Heiden, S., and Born, M. P. (2014). Policy entrepreneurs in sustainability transitions: Their personality and leadership profiles assessed. Environmental Innovation and Societal Transitions, 13: 96-108.

True, J.L. and Jones, B.D. (1999) Punctuated equilibrium theory. In Sabatier, P.A., editor, Theories of the Policy Process, chapter 6, pages 155-188. Boulder, CO: Westview Press, 2nd edition.

Witting, A. (2015). Measuring the use of knowledge in policy development. Central European Journal of Public Policy, forthcoming.

Witting, A. and Dudley, G. (2019). Narrative strategies in the policy process: social and cognitive foundations. Journal of Risk Research (online).

Witting, A. and Moyson, S. (2015). Learning in post-recession framing contests Changing UK road policy. In Schiffino, N., Taskin, L., Donis, C., and Raone, J., editors, Organizing After Crisis, chapter 5, pages 107-129. Peter Lang, Bruxelles, Bern, Berlin, Frankfurt am Main, New York, Oxford, Wien, 1 edition.

Zahariadis, N. (2014). Ambiguity and Multiple Streams. In Sabatier, P.A. and Weible, C.M., editors, Theories of the Policy Process, chapter, pages 25-58. Boulder, CO: Westview Press, 3rd edition.

Zohlnhöfer, R. (2016). Putting Together the Pieces of the Puzzle: Explaining German Labor Market Reforms with a Modified Multiple-Streams Approach. Policy Studies Journal, 44 (1) 83-107. 